\title{
La relación Estado - Economía
}

Jaime Ramírez Plazas*

Artículo recibido: 19/08/2010 Aprobado: 05/10/2010

jarapla@hotmail.com

\section{RESUMEN}

El artículo, producto de una investigación documental, presenta la relación existente entre el Estado y el mercado a la luz de las concepciones ideológicas del administrador del Estado (gobierno) y su aplicación en el caso colombiano.

\section{PALABRAS CLAVE}

Estado, economía, políica, mercado

\section{ABSTRACTS}

This article is a product of desk research, presents the relationship between state and market in light of the ideological concepts of the administrator of the state (government) and its application in the Colombian case.

\section{KEYWORDS}

State, economics, politics, market

\section{INTRODUCCIÓN}

El sistema de economía de mercado como es el nuestro, también conocido como el sistema capitalista, se caracteriza por la existencia de un mercado democrático y representativo en el que existen unas funciones de regulación e intervención de la economía, para garantizar los supuestos básicos del sistema. Sobre la relación Estado - economía en un Estado social de derecho, el presente ensayo se propone examinar las características de las funciones del sistema económico (RAMIREZ PLAZAS, Jaime, s.f.).

El titulo XII de la Constitución Política de Colombia desarrolla el régimen económico y la hacienda pública para un sistema de economía de mercado. La esencia de la economía de mercado descansa sobre la existencia de la propiedad privada, establecido en el artículo 58 de la Carta Política, el cual dispone que se garantice la propiedad privada y los demás derechos adquiridos con arreglo a las leyes civiles, los cuales no pueden ser desconocidos y vulnerados por leyes posteriores. Igualmente descansa sobre la división del trabajo consagrado en el artículo 53, que dispone que la ley que contenga el estatuto de trabajo deba reconocer la igualdad de oportunidades para los trabajadores, una remuneración mínima y vital móvil, proporcional a la cantidad y calidad de trabajo, estabilidad en el empleo, entre otras.

*Profesor de tiempo completo de la Universidad Surcolombiana, Profesor catedrático de Posgrado de la Escuela Superior de Administración Pública-ESAP, Economista de la Universidad de los Andes, con Posgrados en Alta Gerencia - Universidad Surcolombiana, Instituciones Jurídicas Político y Derecho Público, de la Universidad Nacional y Docencia Universitaria de la Universidad Antonio Nariño, Maestría en Derecho Económico de la Universidad Externado de Colombia y doctorado en Sociología jurídica e Instituciones Políticas de la misma Universidad. Autor de los libros: Economía Política, Economía e Instituciones Públicas, Evaluación de los Planes de Desarrollo de Neiva- 1988-2003, Estatuto de Contratación de la Administración Pública, Introducción a la Formulación y Evaluación de Proyectos, Las Finanzas Públicas en Colombia, Manual de Control Presupuestal, Microeconomía para Todos, Macroeconomía Para Todos, 115 preguntas sobre el Ajuste Fiscal, Segunda Recopilación de Costumbres Mercantiles en Neiva y Planeación, Presupuesto y Contratación Municipal, Legitimidad del Estado, legalidad y seguridad democrática. 
El tercer elemento que caracteriza el sistema de mercado es la producción de mercancías bajo la responsabilidad de la empresa, encontrándose este elemento en el artículo 333 el cual establece que la empresa, como base del desarrollo, tiene una función social que implica obligaciones y que la actividad económica y la iniciativa privada son libres, dentro de los límites del bien común; establece así mismo que la libre competencia es un derecho de todos que supone responsabilidades.

El último elemento característico del sistema capitalista es el proceso de acumulación, el cual encuentra expresiones en el artículo 334, cuando se establece que el Estado dirige la economía, para lo cual la intervendrá en la explotación de los recursos naturales, en el uso del suelo, en la producción, distribución utilización y consumo de los bienes y en los servicios públicos y privados para racionalizar la economía. En nuestro ordenamiento jurídico estos elementos básicos convierten el aparato estatal -en términos económicos- en un sistema de economía de mercado.

El comportamiento del Estado en el sistema económico puede ser analizado a través de los enfoques marxista y liberal en sus formas clásicas, keynesiano, neoliberal, neoinstitucional, estructural y neoestructural que vamos a describir en forma muy general.

\section{ELPENSAMIENTOMARXISTA}

El enfoque marxista parte del supuesto que el sistema capitalista descansa en la propiedad privada de los medios de producción, la división social del trabajo, la producción de mercancías y la acumulación.

La organización del trabajo social, se realiza mediante la cooperación, la división del trabajo y la combinación del trabajo con las ciencias naturales, se ha convertido en una realidad más palpable que nunca. El fin del siglo XX permitió establecer que la humanidad sufre los efectos bajo la forma de una muy grave recesión económica, social y política, cuya amplitud era impensable hace 20 años. Esta recesión ha creado el desastre humano que golpea a todos los países capitalistas, con particular fuerza a la juventud, a los segmentos más vulnerables de las clases obreras y a los migrantes.

Estos enfoques resaltan lo que separa la internacionalización de tipo doméstico de aquel en el cual dominaba las estrategias propiamente globales y las formas de organización de grupo de firmas -red-. La globalización es la expresión de nuevas relaciones del capital y el Estado en el ámbito nacional, particularmente entre el capital industrial y el capital monetario.
El capital fuertemente centralizado y concentrado, comprometido en la producción o que se valoriza bajo la forma de capital dinero, ha barrido la mayor parte de las limitaciones que se le habían impuesto por los Estados nacionales después de los años 30 del siglo XX y de la segunda guerra mundial. A partir de los años 70 , el capital ha roto la faja de relaciones sociales, de leyes y de reglamentos en donde se habían intentado encerrarlo con la intención Keynesiana de controlarlo.

La globalización es sinónimo de una subordinación a los mecanismos sobre los cuales tienen muchos ascendientes un creciente número de responsables políticos, empresarios y banqueros. El retorno al mercado no es casual y solo refleja hasta qué punto la economía mundial globalizada ha aumentado la empresa del fetichismo de la mercancía, que se expresa en la mundialización de las operaciones del capital bajo la triple forma de capital industrial, de capital concentrado comprometido en los negocios y en la gran distribución y sobre todo, cada día se torna más presente, bajo la forma de capital dinero concentrado.

El dinero se valoriza en el seno de la esfera financiera, pero se nutre en la esfera de producción donde se forma el valor, la plusvalía y las otras variables de sobre producto. 
La mundialización exige la reapropiación de útiles analíticos claros para aprender lo que es una totalidad sistemática (CHESNAIS, Francois, 1996). Con base en lo anterior, el capital debe ser pensado como una unidad diferida y jerarquizada, conformada por el capital industrial, el capital comercial y el capital dinero, los cuales se diferencian internamente; esta diferenciación conduce a profundas contradicciones pero todas descansan en la propiedad privada.

La mundialización del capital se expresa en la progresión cuantitativa y cualitativa del movimiento descentralización y concentración del capital industrial. Los grandes grupos parecen más fuertes que nunca. Los son sin duda alguna, en relación con las empresas y países menos fuertes, a los que pueden dictar sus contradicciones, pero su grado de financiación se traduce en la fuerza de la presión que el superconcentrado capital dinero ejerce sobre ellos.

El movimiento de centralización y concentración de capital se ha desarrollado en los últimos 10 años a una escala sin precedentes, en tanto que el proceso propiamente internacional en el marco que denomina la Triada, este movimiento ha sido impulsado por las exigencias de la competencia, que obligan a los grupos más fuertes a arrebatar a las firmas absorbidas sus cuotas de mercado y a reestructurar y racionalizar sus capacidades de producción. Además ha sido favorecido y facilitado por las políticas de liberalización, de desreglamentación y de privatización.

La concentración de los medios de producción en pocas manos ha alcanzado dimensiones descomunales, desbaratando todos los pronósticos optimistas respecto a una posible desconcentración del poder económico.

Lo que es característico de la fase de la mundialización del capital, es la extensión de estructuras de ofertas muy concentradas en la mayor parte de las industrias de fuerte intensidad en investigación y desarrollo o en la alta tecnología, así como en los numerosos sectores industriales de fabricación en gran escala.
El oligopolio es un lugar de competencia feroz, pero también de elaboración entre grupos, los cuales reconocen su dependencia mutua del mercado por medio de toda clase de acuerdos, muchos de los cuales están cobijados por las legislaciones anti oligopólicas. Las relaciones constitutivas del oligopolio se convierten por sí mismas, en una importante barrera de entrada y además otros elementos pueden reforzar esas barreras.

El capital mercantil o capital comercial es una perfecta expresión de la fuerza que éste ha adquirido en los últimos tiempos a partir de las deslocalizaciones, que resultan del negocio internacional que provoca el aprovisionamiento en productos industriales estandarizados donde los costos salariales son menores.

Este proceso se da en términos de insumos y productos finales de consumo de masa que las grandes cadenas comerciales o los hipermercados pueden buscar muy lejos, estableciendo sus propios términos de subcontratación con productos locales comercializados por los productores en todas las grandes cadenas de almacenes.

La explotación de transacciones financieras ha sido unos de los hechos destacados de la década de 1980 y ya ha dejado su sello en la primera mitad de los años 90. La mundialización del capital está más avanzada en la esfera financiera que en cualquier otra esfera y en actividades marcadas por la búsqueda de liquidez, la rentabilidad a corto plazo y un grado muy elevado de movilidad en las formas comprometidas con la denominación de procedimientos de arbitraje entre activos. Los mercados financieros mundializados se presentan, como una arena organizada, de suerte que las masas concentradas de capital- dinero tiene todo el tiempo para valorizarse, conservando un grado de liquidez muy elevado, gracias a lo cual coloca préstamos a corto plazo y se apropian de beneficios financieros puros, que resultan de operaciones efectuadas exclusivamente dentro de la esfera financiera.

La existencia de tasas de interés reales positivas es una de las condiciones y el cumplimiento del pago 
del endeudamiento de los Estados para luchar contra la inflación parece haberse convertido en el objetivo prioritario de numerosos gobiernos importantes, de suerte que la coyuntura mundial ha adquirido una tonalidad deflacionista.

La importancia de la plusvalía no significa que los capitales sean indiferentes a la plusvalía absoluta. La cual ha tomado un importante curso durante los últimos 15 años, como consecuencia de la competencia imperialista de cada grupo individual y de cada país, mediante la reducción del precio de la fuerza de trabajo, a través de la voluntad deliberada de disminuir el precio de la misma por debajo de su valor, atacando el salario, en todas sus formas.

La economía mundial ha entrado en una fase de débil crecimiento mundial, inestable y grandemente conflictivo, marcada por un desempleo estructural elevado, una deflación rampante y una competencia intensa. En el corazón de los encadenamientos acumulativos se encuentran la conjugación entre las consecuencias de los recientes cambios tecnológicos y la desmundialización del capital.

La destrucción de empleos en una cantidad muy superior a la creación, no es únicamente el resultado de una especie de fatalidad atribuible a la tecnología. Resulta de la movilidad de acción, casi total, que el capital ha recuperado para invertir y desinvertir a su antojo en su país o en el extranjero y de la liberalización de intercambios comerciales. El efecto de estos factores, está acentuado de forma creciente por el cambio de propiedad del capital industrial, inclusive en grupos en los cuales la rentabilidad ha sido restablecida, por parte de los nuevos propietarios, para reducir todavía más los costos y reduciendo los efectos y efectivo automatizando a la máxima velocidad.

La movilidad del capital permite a las empresas forzar a los países a homogeneizar sus legislaciones del trabajo y de protección social con las del Estado cuyas leyes le sean más favorables. La influencia de la mundialización del capital sobre el consumo de los hogares se efectúa por dos canales principales.
El primero de ellos es la disminución de los ingresos provenientes del trabajo asalariado y en segundo lugar en la redistribución del ingreso nacional a favor de ingresos rentísticos que se han desarrollado en los países a partir del año 1980.

Esta mundialización va a debilitar el gasto público por varios mecanismos, como son la reducción de los ingresos impositivos, el desempleo, el aumento de la deuda pública, con tasa de interés positiva, con lo cual se disminuye la capacidad de intervención del Estado para sostener la demanda. La crisis fiscal del Estado, conjugada con los efectos de las políticas neoliberales, conduce a la reducción del empleo en el sector público y a la aceleración de privatizaciones y desreglamentaciones.

\section{PENSAMIENTO CLÀSICO}

El pensamiento clásico tiene como exponente a Adam Smith con su obra "la Riqueza de las Naciones" en la cual desarrolla la teoría de la mano invisible, y a David Ricardo, con su obra "Principios de Economía Política y Tributación", en la cual desarrolla la teoría del valor trabajo, y a quienes se les considera los padres del pensamiento económico, pues con ellos se inicia la forma consolidada en análisis de los fenómenos económicos. Para el pensamiento clásico, el Estado tiene una mínima participación en el proceso económico, pues el mercado descansa sobre la racionalidad de los oferentes y demandantes que hace innecesaria la presencia directa del Estado en el mercado.

Para los clásicos, el mercado era el instrumento ideal por excelencia para asignar bienes y servicios a partir de la racionalidad de los agentes que lo conforman, es decir, de los demandantes y oferentes, los cuales, buscando cada uno maximizar su conducta, termina a través del mercado maximizando el bienestar de la sociedad. Esto es lo que se conoce con el nombre de la mano invisible. Es bueno recordar que la racionalidad de los demandantes y oferentes es la base para asignar eficientemente los productos del mercado, lo cual equivale a decir, que los demandantes siempre estarán buscando maximizar su nivel de 
satisfacción en el consumo de bienes y servicios, y los oferentes siempre estarán, buscando maximizar su nivel de ganancia con el proceso de producción.

Si aceptamos la racionalidad del mercado, (ARRELLANO, Rolando, 1993) el Estado no tiene necesidad de intervenirlo, pues su conducta conduciría a generar imperfecciones o distorsiones en el mismo y con ello a no asignar eficientemente los bienes y servicios. La función del Estado se debe limitar a facilitar el funcionamiento de los mercados mediante el manejo de la moneda como variable exógeno del sistema económico, la construcción de vías públicas que facilite la realización de las mercancías y la protección de las personas discapacitadas, que carecían de una conducta racional para participar en el mercado, y a regular la conducta de los agentes del mercado. Dadas las limitadas funciones del aparato estatal, el mismo demanda poco recursos para su funcionamiento y en consecuencia los impuestos solo tenían, como finalidad garantizar el funcionamiento del aparato estatal. (RICARDO, David, 1995)

Para los clásicos, el mercado estaba conformado por una parte real y una parte nominal, siendo esta ultima determinada por la parte real. El mercado real estaba conformado por el mercado laboral y el mercado del producto. El supuesto sobre el cual descansaba el mercado laboral era la flexibilidad de los salarios, es decir, que los mismos podían subir o bajar sin ninguna restricción, lo cual conduciría al equilibrio de dicho mercado y, por lo tanto, al pleno empleo, razón por la cual, para el modelo clásico, la economía siempre estaría en pleno empleo, pues quien quisiera trabajar al salario de equilibrio lo puede hacer. Garantizado el equilibrio del mercado laboral y con el pleno empleo de conformidad con la teoría del valor trabajo.

La contrapartida de la parte real del mercado era la parte nominal conformada por los mercados de dinero y el mercado financiero. El primero de ellos que se utilizaba para realizar transacciones, está conformado por la oferta monetaria como variable exógena determinada por la autoridad monetaria del país de origen gubernamental, quien era la encargada de suministrar a la economía la cantidad necesaria para realizar las transacciones de las mercancías con base en la velocidad de circulación de dinero.(RAMIREZ PLAZAS, Jaime, 2002)

La oferta monetaria tenía como contrapartida la demanda conformada por la velocidad de circulación del dinero determinada por los hábitos de pagos y los hábitos de gasto, y el volumen de producción de la economía.

El mercado financiero está conformado por el ahorro y la inversión, los cuales dependían de la tasa de interés y con ello la rentabilidad de los proyectos, el ahorro, que es parte del ingreso no consumido que está en función directa de la tasa de interés, lo cual significa que a mayor tasa de interés mayor nivel de ahorro, mientras tanto, el nivel de inversiones está en función inversa de la tasa de interés, de tal forma que, a menor tasa de interés mayor nivel de inversión, con lo cual se garantiza un aumento en el volumen de producción.

La vigencia del pensamiento clásico se vio amenazada por dos fenómenos (RAMIREZ PLAZAS, Jaime, 2002) a saber:

1. El desarrollo del proceso de industrialización generado por las innovaciones tecnológicas que conducirían a un incremento de la productividad, y con ello, al aumento en el volumen de producción a menores costos que permitirían más ganancias, pero igualmente generaría desempleo, pues sería sustituído el trabajo por el capital, así mismo, surgiría las formas imperfectas de mercado como los oligopolios y los monopolios que siempre actúan a favor de los productores y en contra de los consumidores mediante la reducción de las cantidades de bienes y servicios que llevan al mercado y con ello al aumento de los precios.

2. Fue el surgimiento de Rusia como Estado socialista en la segunda década del siglo XX bajo la inspiración del pensamiento marxista- leninista, con lo que se rompían los supuestos fundamentos del sistema capitalista que eran la defensa de la propiedad y de la democracia, para ser sustituídos por la propiedad estatal de los medios de 
producción y la dictadura del proletariado.

En los años treinta del siglo $X X$, se presenta la gran recesión económica mundial generada por una reducción en volumen de producción, altas tasas de desempleo y reducción en el nivel de precios, fenómenos estos que no podían ser explicados con el modelo clásico y con lo cual van a aparecer los nuevos hechos en las conductas de los agentes del mercado, que conducen a una modificación de los supuestos sobre los cuales descansaban los mercados en el modelo clásico y, con ello, su incapacidad para explicar la nueva realidad económica.

\section{PENSAMIENTO SOCIALDEMOCRATA}

La gran depresión económica mundial de los años treinta del siglo XX, permite el surgimiento de la teoría keynesiana que busca reformular la teoría clásica a partir de la nueva realidad económica que permitirá garantizar el funcionamiento de la economía de mercado, mediante una revisión de los supuestos básicos sobre los cuales descansa, es decir, la función social de la propiedad privada y la ampliación de la democracia mediante la extensión de la igualdad a todos los ciudadanos para la construcción del Estado.

Keynes formula la redefinición de los supuestos básicos del sistema capitalista después de observar el surgimiento del sistema socialista en la Rusia zarista que amenazaba con extenderse por todo el mundo y de observar que como consecuencia de la aparición de los sindicatos habían surgido las leyes laborales que habían conducido a la inflexibilidad de los salarios y con ellos a la aparición del desempleo. Los sindicatos surgen como consecuencia de la socialización de la producción capitalista, que en su afán de obtención de ganancias produce un conjunto de mejoras en el proceso de producción como la mecanización y la producción en serie conocidos como taylorismo y aforismo. (ACKLEY, Gardner, 1968).

Estos procesos generan la socialización del trabajo, que le va a permitir a la clase obrera realizar el paro en el proceso de producción para buscar mejoras en las producciones de salarios para él y su familia; la lucha de trabajadores por mejoras en las condiciones de trabajo, salario y estabilidad laboral, se convirtieron en normas de obligatorio cumplimiento por parte de los patrones, con lo cual el salario tiene un tope mínimo a partir del cual se debe llevar a cabo la contratación de trabajadores y con lo cual surge la inflexibilidad de los trabajadores a la baja, pero la inflexibilidad al alza, que se va a convertir según la teoría keynesiana en obstáculo al pleno empleo y con el surgimiento del desempleo.

Para keynes, el mercado de dinero era necesario revisarlo por la aparición de los especuladores que actuaban en el mercado mediante el retiro de grandes cantidades de dinero de la circulación y con lo cual creaban una modificación en los precios de los bienes y servicios, y con ello una variación en la tasa de interés, es decir, que el atesoramiento considerado como algo irracional en el modelo clásico, se convierte en algo racional y rentable para el nuevo modelo.

Finalmente, en el mercado financiero se observa que los inversionistas, cuando van a llevar a cabo nuevos proyectos no solo miran la rentabilidad de los mismos, sino también, las expectativas que sobre el futuro tengan, pudiendo ser las mismas de optimismo y pesimismo. Si existe optimismo en los inversionistas y los proyectos son rentables económicamente, entonces se produce un aumento en el nivel de inversión y con ello un aumento en el volumen de empleo, así como en la producción. Pero si se presenta pesimismo sobre el futuro por los inversionistas, a pesar de ser rentables los proyectos ellos reducirán el nivel de inversión y aparece 0 aumenta el desempleo y baja el volumen de producción. Lo anterior equivale a decir que el riesgo va a aparecer como un factor que desestimula la inversión, pues crea pesimismo en los inversionistas.

Con base en la anteriores realidades, keynes redefine el modelo clásico de los mercados así: lo primero que establece es la interdependencia de los mismos de tal forma que lo que suceda en cualesquiera de los mercados afectada el modelo; lo segundo es que el mercado laboral, va a 
depender de los salarios reales con salarios nominales inflexibles a la baja y flexible al alza fijado en forma exógena por el gobierno fruto o nó del proceso de concertación entre centrales obreras, gremios y el gobierno y va a surgir el equilibrio en el mercado laboral, pero con desempleo, con lo cual se rompió el supuesto clásico de equilibrio con pleno empleo.

Como consecuencia del equilibrio con desempleo se va a encontrar una reducción en el volumen de producción que depende del empleo, pues al disminuir éste disminuye el producto; en tercer lugar, el mercado de dinero con la presencia de los especuladores en su demanda va tener tres componentes: una demanda para transacciones y una demanda para especulación y una demanda de crédito para el gobierno con destino a la financiación del gasto público y finalmente, con el mercado financiero se puede observar que él mismo no solamente depende de la rentabilidad de los proyectos, si no de las expectativas que tengan los inversionistas sobre el futuro.

El papel del Estado en el modelo keynesiano (PRADHAN; Sanjay, 1997) también va a variar frente al pensamiento clásico, que consideraba que el papel del Estado era regular la actividad económica, mientras que ahora tiene como función nueva la intervención económica directa, a través de la redistribución del ingreso, la estabilidad económica y el desarrollo económico, lo cual va a determinar mayores recursos para el aparato estatal que van a provenir de los impuestos, tasas, contribuciones, el crédito y las ganancias provenientes de las actividades industriales y comerciales que realiza.

Como consecuencia de lo anterior, los impuestos, además de servir para garantizar el funcionamiento del Estado, se utilizan como instrumento de la política económica, con los cuales se puede estimular o desestimular una actividad. El proceso de intervención del Estado se lleva a cabo a través del incremento en el gasto público, con lo cual se aumente el nivel de inversión en la economía y a través de ella se presenta un incremento en la demanda agregada, cuya finalidad es aumentar el empleo y, a través de este mecanismo, aumentar el volumen de producción de la economía como base fundamental para poder llevar a cabo el desarrollo económico (LECHNER, Norbert, 1992).

Al modelo keynesiano se le responsabiliza de generar un gran déficit fiscal, pues el proceso de intervención del aparato estatal para corregir las fallas del mercado conduce a que los ingresos que recibe el fisco no sean suficientes para garantizar el trámite de las demandas sociales. Viéndose obligado el Estado a encontrar créditos para satisfacer las necesidades sociales creándose de esta forma el endeudamiento público y el déficit fiscal, ya que los ingresos del Estado son menores que el gasto público.

Los economistas keynesianos insisten en que las tendencias a las crisis son inherentes a la economía capitalista y la eficiencia de los cálculos de beneficio de los agentes económicos y privados son la base de la inversión, razón por la cual se opone a la inversión estatal directa de las inversiones en el sentido de una planificación compresiva de la cantidad, calidad, lugar y tiempo de las inversiones. Los keynesianos tienen, pues, por necesario un control estatal en curso de la economía, con el uso de instrumento de control indirecto y global, los cuales ejercen una influencia efectiva sobre la aplicación de los cálculos de rentabilidad de los agentes económicos privados, pero al poco tiempo merman lo menos posible la supuesta eficiencia de las decisiones capitalistas.

El pensamiento keynesiano respondía a la necesidad de una ideología social demócrata como un camino de intermedio entre el socialismo existente y el capitalismo explotador y siempre sometido a la crisis del periodo de la preguerra. Dicho en términos sencillos, se trataba no de una superación si no de la humanización de la forma capitalista. Y aun esto, solo en la medida en que con ello no quedara quebrantado el potencial que tiene el capitalismo para generar bienestar, siendo los fines prioritarios la extensión del sistema de seguridad social, la igual participación de todos los habitantes en las prestaciones de un sistema educativo y un sistema de sanidad de calidad 
suficiente y la mejora de la infraestructura pública (CHESNEIS, Francois, 1997).

\section{EL PENSAMIENTO NEOLIBERAL}

El creciente déficit fiscal, así como los altos niveles de endeudamiento público sumado a la terminación de la guerra fría entre este y oeste, hacía necesario revisar las políticas estatales sobre el gasto público buscando restablecer el equilibrio económico de las finanzas públicas.

La economía Neoclásica, (Meidner, 1978) se orienta por los principios de que la economía ideal de mercado tiene un equilibrio en que se hace uso de todas las posibilidades de producción, todos los que buscan trabajo lo encuentran y todos los deseos realizables de consumo se cumplen. Las condiciones reales necesarias para una aproximación satisfactoria al ideal son simplemente una competencia que pueda de verdad funcionar y la flexibilidad de los precios relativos. Para esta teoría, se exige una actividad política de competencia por parte del Estado, el cual debería intervenir lo menos posible en la economía, y las intervenciones inevitables serían para la corrección de los efectos externos del mercado.

Con la culminación de la guerra fría, el modelo económico centralista abre los espacios al mercado para su desarrollo en toda la tierra y la utilización de toda la tecnología de comunicaciones que se habían preparado para la guerra sería utilizada ahora para integrar a la humanidad; este fenómeno se conoce con el nombre de globalización.

La globalización implica las existencias de fuerzas exógenas que de una forma u otra marca de manera rigurosa y específica los lineamientos a seguir en materia de política económica e internacional. Se trata de una noción excluyente de las fuerzas sociales y de la dinámica interna de la sociedad civil respectiva que es precisamente la más afectada.

La globalización encuentra la expresión en dos procesos denominados geoeconomía y geopolítica. La primera tiene como identificación del interés del mercado mundial y se encuentra representada por los países desarrollados considerados como los siete grandes: Estados Unidos, Japón, Alemania, Italia Inglaterra, Francia y Canadá.

El proceso de la geoeconomía es el reconocimiento de un mercado mundial para lo cual se hace necesario modificar el sistema de barreras arancelarias que obstruyan el normal desarrollo de los mercados; se soporta por la apertura económica, por medio de la cual los países tienen que ofrecer todas las condiciones necesarias en materia de normas e impuestos que faciliten el ingreso de las mercancías a todos los países. Mientras la geopolítica es la orientación de la política mundial por parte de tres potencias que se reparten territorios como son Japón sobre Asia, Alemania sobre Europa y Estados Unidos sobre el resto del mundo.

El neoliberalismo implica una reedificación de la conducta del Estado en el manejo de la economía, (ESTRADA ALVAREZ, Jairo, 1998) para lo cual se parte de un hecho: del déficit fiscal en las finanzas públicas y con altos niveles de endeudamientos, que se han convertido en obstáculos para llevar a cabo el proceso de acumulación capitalista.

El aparato estatal cumple las funciones de intervención y de regulación, pero dichas funciones se realizan a partir del reconocimiento del mercado como el instrumento ideal por excelencia para asignar precios y cantidades, de tal forma que las fallas del mercado las corrige el Estado devolviéndole las funciones que le habían arrebatado.

Mediante la focalización de la población con necesidades básicas insatisfechas, las cuales le permiten estratificarlas y a partir de allí identificar los sectores sujetos de las políticas públicas a los cuales se les concede el subsidio para acceder a resolver las necesidades sociales.

Con la devolución de funciones al mercado por parte del Estado, se hace necesario realizar los activos con los cuales se encontraban 
cumpliendo dichas funciones, lo que le va a permitir recibir ingresos que se van a destinar a reducir el déficit fiscal, es decir, el desarrollo del proceso de privatizaciones de las funciones públicas; podemos decir, que para reducir el déficit se utilizan unos instrumentos fiscales del lado del ingreso como es el incremento de las rentas vía reducción de las exenciones, descuentos, que permitan aumentar la base impositiva, la lucha contra la evasión tributaria y el mantenimiento o reducción de las tarifas de los impuestos; adicionalmente se cuenta con los ingresos provenientes de las privatizaciones.

Por el lado del gasto se propone una reducción del tamaño del aparato del Estado generado como consecuencia de la cesión de las funciones al mercado y un manejo adecuado del sistema de endeudamiento público, buscando sanear las finanzas públicas.

Desde el lado de la política, la tarea esencial del Estado es garantizar la legitimidad, para lo cual se busca la consolidación de la democracia, recurriendo para ello al uso de los siguientes instrumentos: la protección y defensa de los derechos fundamentales más conocidos como los derechos humanos, el derecho internacional humanitario, la consecución de una política del medio ambiente, la ampliación de la participación política que permita acercar más el Estado a la sociedad civil, con mecanismos como la sesión a las regiones de funciones y competencias suyas para ser realizadas por las autoridades locales que han sido electas por sus propios ciudadanos y que gozan de autonomía administrativa, en el marco de la Constitución y de la Ley. Pero, igualmente, es responsabilidad del Estado adecuar la normatividad al proceso de funcionamiento del mercado para garantizar la acumulación, la cual se lleva a cabo con el proceso de flexibilización laboral, que permite restablecer el equilibrio en el mercado laboral y el consiguiente aumento en el volumen del producto.

\section{EL PENSAMIENTO ESTRUCTURALISTA}

Esta concepción surge en América Latina como consecuencia de la conferencia económica para
América Latina- CEPAL- en los años sesenta del siglo XX, y según la cual el desarrollo económico de América Latina no se puede explicar con los modelos económicos que tuvieron origen en Europa y Norteamérica en países con un elevado nivel de desarrollo económico y características orográficas, climáticas y culturales muy diferentes a América latina, siendo necesario ajustar dichos modelos a nuestra realidad en caso de querer implementarlos.

Según este enfoque, es necesaria una activa participación del Estado en el proceso de constitución de la industria nacional a partir del sector agropecuario y minero donde tenemos ventajas comparativas, mediante una política proteccionista que conduce a un Estado grande que demanda grandes recursos para el cumplimiento de tal fin.

\section{ELNEOESTRUCTURALISMO}

Es una corriente latinoamericana del pensamiento que afirma que los problemas económicos y la condición de subdesarrollo que aún prevalece en nuestros países no se deben a distorsiones inducidas por la política económica, si no más bien que son de origen histórico y de índole endógena y estructurada. Los elementos que caracterizan la economía desde los años 80 son las siguientes:

1. La vigencia de un patrón de inserción externa que dada las tendencias del comercio y del sistema financiero internacional, conduce a una especialización empobrecida.

2. El predominio de un patrón productivo desarticulado, vulnerable y muy heterogéneo y concentrador del progreso técnico, incapaz de absolver productivamente el aumento de la fuerza de trabajo.

3. La persistencia de una distribución del ingreso muy concentrada y excluyente, que evidencia la incapacidad del sistema para disminuir los niveles de pobreza.

Como consecuencia de lo anterior, se necesita generar un proceso dinámico que impulse progresivamente la economía hacia la curva de 
posibilidades de producción y de desplazamiento hacia nuevas fronteras productivas, que permitirán su inserción en la economía internacional. El mercado se debería complementar en medidas significativas con una acción estatal activa y dinámica, de manera que el Estado, aparte de sus funciones clásicas, incluye dentro de las capacidades administrativas las siguientes:

1. La promoción de mercados ausentes como son los mercados de capital de largo plazo y el mercado de divisas a futuro.

2. El fortalecimiento de los mercados incompletos como el tecnológico.

3. La superación de las distorsiones estructurales, como la concentración de la propiedad, la segmentación del mercado de capital y de trabajo, la heterogeneidad de la estructura productiva y el carácter asimétrico del sector externo.

4. La eliminación de la fallas más importantes de mercados de divisas, derivadas de los rendimientos a escala, las externalidades y el aprendizaje industrial o del sector externo.

Los anteriores lineamientos de la conferencia económica paraAmérica latina-CEPAL-configuran la estructura productiva que permite crecer con dinamismo y asegura una inserción eficiente de nuestros países en la economía mundial, incrementando la generación de empleo productivo, reducción de la heterogeneidad estructural y, de este modo, mejorar la distribución del ingreso y lidiar la situación de pobreza en que vive gran parte de la población latino americana.

Como acciones urgentes para alcanzar esta meta de justicia social (CUEVAS, Homero, 1.977) se sugieren tres áreas en las cuales puede actuar la selectividad efectiva de la gestión estatal a saber:

1. Minimizar el impacto de los problemas del orden externo sobre los grupos más pobres y vulnerables, por la vía de apoyar tanto la producción como los ingresos y los servicios sociales.

2. Disminuir los costos de reubicación de la mano de obra asociada a las reformas estructurales inherentes al ajuste.

3. Facilitar la erradicación de la pobreza y de la concentración excesiva del ingreso y la riqueza una vez reanudado el crecimiento.

La función principal del Estado puede definirse como la de plantear una visión estratégica de proceso de desarrollo, reordenar y mantener los incentivos y los precios relativos de la economía de manera coherente con esa visión y comprometer, constructivamente, mediante el diálogo y la concentración, a todos los sectores sociales y políticos con esa estrategia. Como consecuencia de lo anterior es necesario la intervención del aparato económico a través de:

1. Atacar las principales distorsiones de la economía como consecuencia de la limitación de recursos por parte del sector público.

2. Descentralizar y despolitizar la gestión pública para reducir la sobrecarga que recae sobre el gobierno central y así mejorar su eficacia.

3. Creación de mecanismos automáticos que permitan eliminar los contrapesos institucionales de la intervención.

\section{INSTRUMENTO DEL ESTADO PARA REALIZAR LA INTERVENCIÓN}

La planeación en Colombia adquirió categoría constitucional con el artículo 339, que estableció la obligatoriedad del Estado de tener un plan de desarrollo conformado por una parte general en la cual se señala los propósitos y objetivos nacionales de largo plazo, las metas y prioridades de la acción estatal a mediano plazo y a las orientaciones generales de la política económica, social y ambiental que serán adoptadas por el gobierno y un plan de inversión pública que contiene los presupuestos plurianuales de los principales programas y proyectos de inversión pública nacional, así como la especificación de los recursos requeridos para su ejecución.

El plan tiene aplicación en los diferentes niveles de administración, es decir, tanto en el nivel nacional como en el nivel territorial. Los planes territoriales deben elaborarse en armonía y concordancia en el 
plan nacional, pero soportados en voto programático del candidato ganador.

Las entidades territoriales (municipios, distritos, asociación de municipios, territorios indígenas, provincias, áreas metropolitanas, departamentos y regiones), elaborarán y adoptarán de manera concertada entre ellas y el gobierno nacional, planes de desarrollo, con el objeto de asegurar el uso eficiente de los recursos y el desempeño adecuado de las funciones que les hayan sido asignadas por la Constitución y la Ley.

La Ley Orgánica del Plan (Ley 152 de 1994), regula lo correspondiente a la programación, aprobación, modificación del plan en los niveles nacionales y territoriales; esta regulación debe comprometer la administración pública.

El instrumento para la ejecución del plan es el presupuesto, de conformidad con lo dispuesto por el artículo 346 de Carta constitucional; el cual debe contener la totalidad de los gastos que el Estado pretende realizar durante la vigencia fiscal respectiva. El presupuesto no se puede analizar como Ley formal, pues la misma solamente tiene vigencia por el año fiscal, siendo necesario el estudio de la Ley Orgánica de Presupuesto que es la que establece los términos de preparación, aprobación, ejecución y control que se debe tener en cuenta al elaborarlo.

Desde esta perspectiva, cualquier distanciamiento de los miembros de la corporación pública de elección popular de la norma orgánica vigente durante el proceso de tramite, aprobación y expedición de la norma anual de presupuesto, bien sean contrariando, desconociendo o adicionando nuevos conceptos, implicaría una violación que generaría la inconstitucionalidad o legalidad de la norma expedida.

La norma orgánica de presupuesto es para los miembros de una corporación pública de elección popular, un marco de referencia, que limita y condiciona su propia capacidad y alcance para desarrollar la materia; es una norma cuyos contenidos constituyen una condición previa, no posterior, del proceso de producción de las normas inferiores que desarrollan la materia que regula.

El contenido de la Ley Orgánica de Presupuesto, regula lo correspondiente a la programación, aprobación, modificación, ejecución de los presupuestos de la Nación, de las entidades territoriales, de los entes descentralizados de cualquier nivel administrativo, y su coordinación con el Plan Nacional de Desarrollo, así como también la capacidad de los organismos y entidades estatales para contratar (artículo 352).

La importancia del presupuesto en la sociedad moderna radica en la movilización de grandes volúmenes de recursos, creando con ello una variable importante desde el punto de vista económico, tanto cuantitativo como cualitativo; así mismo el presupuesto provee las normas legales para que la ejecución del gasto público se controle y se evalué su eficiencia. (RAMIREZ PLAZAS, Jaime, 2007)

El Congreso de la República ha expedido las leyes 38 de 1989, 179 de 1994, 225 de 1995 y 819 de 2003, que conformarán el Estatuto Orgánico del Presupuesto, las cuales se encuentran compiladas en el derecho - Ley 111 de enero 15 de 1996. Así mismo, el gobierno nacional expidió el decreto 568 de marzo 26 de 1996, reglamentario de las leyes orgánicas del presupuesto. Podemos decir que en estos dos decretos se encuentra todo lo concerniente a las normas de presupuesto como instrumento del plan de desarrollo en el nivel nacional. En el nivel territorial se agrega la Ley 617 del 2000 que constituyen los fundamentos para expedir la ordenanza y el acuerdo orgánico de presupuesto.

Para llevar a cabo un acercamiento del Estado con la comunidad se hace la distribución de recursos y competencias entre el nivel central y las entidades territoriales para lo cual el artículo 356 de la Constitución determina los recursos del Sistema General de Participaciones, destinados a salud y educación, con excepción de la universitaria y propósito general, que se reparten entren los departamentos, los distritos, y los municipios, con 
destino al gasto público social conformado por salud, educación, recreación, cultura, deporte, vivienda, agua potable y saneamiento básico.

La Ley 715 de 2001, orgánica de competencias y recursos, establece el procedimiento para determinar la distribución entre los departamentos y distritos de los recursos del sistema General de participaciones, la destinación entre los diferentes programas que configuran cada uno de los sectores así como los instrumentos de eficiencia administrativa y esfuerzo fiscal de dichas entidades que permiten aumentar su participación; lo mismo sucede con lo ingresos de los municipios, a los cuales se les señala el porcentaje para cada sector en el área urbana como en la rural, y los criterios para distribuir los recursos entre los municipios y cabildos indígenas que son el número de habitantes con necesidades básicas insatisfechas, la población total, el esfuerzo fiscal y eficiencia administrativa.

El manejo de los servicios públicos es inherente a la función social del Estado, el cual tiene la obligación de asegurar su prestación eficiente a todos los habitantes del territorio nacional, de conformidad con lo dispuesto por el artículo 365 de la Carta, pudiendo ser prestados por el Estado directamente 0 indirectamente por comunidades organizadas, pero manteniendo el Estado la regulación de los mismos. La organización legal de los servicios públicos está compilada en la Ley 142 de 1994.

Finalmente los artículos 371 y 372 de la Constitución establecen que el manejo y emisión de la moneda, los cambios internacionales, la administración de las reservas internacionales, el servicio de crédito en última instancia al sistema bancario y el crédito, son funciones del Banco de la República ejercidas en coordinación con la política económica general fijada por el gobierno nacional.

\section{INSTRUMENTODELADEMOCRACIA}

La democracia se soporta en la libertad de las personas a quienes se les reconoce la ciudadanía plena como requisito para su participación en el proceso político con el cual se constituyen las autoridades estatales. Nuestra carta constitucional determina en el artículo 3 la soberanía popular, la cual puede ser ejercida en forma directa o por medio de sus representantes, que de conformidad con el artículo 133 son los miembros de las corporaciones públicas quienes actúan consultando la justicia y el bien común, siendo responsables ante la sociedad y sus electores del cumplimiento de las obligaciones propias de su investidura.

Como se puede ver, con la voluntad popular se eligen los gobernantes y los miembros de las corporaciones públicas, responsables de la producción de normas y la ejecución de las políticas públicas emanadas de dichas normas, por parte del nivel ejecutivo, también electo popularmente.

El Congreso de la República, conformado por el Senado y la Cámara de Representantes, como corporaciones de elección popular por medio de leyes, tienen unas funciones económicas, establecidas en la Constitución en el artículo 150 numeral 19 , en materia de crédito público, comercio exterior, actividad financiera, bursátil, aseguradora, la concerniente a materia salarial y prestaciones; numeral 21, en materia de intervención económica, fijando los limites y alcances de la libertad económica; el numeral 22, que permite determinar las leyes relacionadas con el Banco de la República; y el 22 sobre el régimen de propiedad industrial, marcas, patentes y otras formas de propiedad intelectual.

Sin embargo estas leyes sólo pueden ser dictadas por el Congreso a iniciativa del gobierno, de conformidad con lo dispuesto por el artículo 154 de la Carta y no están sujetas a modificación por el pueblo en forma directa por el mecanismo de referendo, como lo estableció el artículo 170.

Al no existir la participación popular en materia económica, la misma sólo se limita al espacio político, la cual encuentra en el titulo IV de la Constitución las formas sobre la participación política; sin embargo, es bueno acotar que a lo largo de la Carta encontramos un conjunto de mecanismos de participación política de la comunidad y los ciudadanos. El artículo 103 señala 
los principales mecanismos de participación ciudadana, como son: el voto, el plebiscito, el referendo, la consulta popular, el cabildo abierto, la iniciativa legislativa y la revocatoria del mandato. El mecanismo de participación comunitaria por excelencia es la tutela.

Podemos iniciar brevemente los campos en donde la participación alcanza rango constitucional, así (VARGAS VELÁZQUEZ, Alejo, 1996):

1. En los servicios públicos domiciliarios, los artículos 78 sobre consumidores y usuarios; el 365, sobre los servicios públicos; y el 369 , sobre las empresas estatales.

2. En materia de servicios sociales, los artículos 49, sobre servicios de salud; el 51, sobre el derecho a la vivienda; el 52, sobre recreación, deportes y tiempo libre, los artículos 68 y 69 , sobre los servicios educativos, el 79 , sobre el medio ambiente; el 247, sobre la seguridad y lajusticia.

3. Para las poblaciones especiales contamos los artículos 40, sobre la participación femenina; el 45, sobre los jóvenes; el 46, sobre la tercera edad; y el 329, de las comunidades indígenas.

4. Sobre la producción y el trabajo encontramos los siguientes artículos: el 53, que hace referencia al estatuto del trabajo; el 55 , sobre la concertación de conflictos; el 56, sobre los salarios; el 57, referente a la gestión de empresas; el 58, acerca de las formas asociativas y solidarias; el 64, sobre los trabajadores agrarios; y el 333 sobre el desarrollo empresarial y solidario.

5. Acerca de la gestión pública y el control tenemos los artículos 270, sobre la vigilancia; y el 369, sobre la gestión y fiscalización.

6. En planeación se da la participación con los artículos 340, que determina la conformación del Consejo Nacional de Planeación; y el 342, acerca de los procesos de participación.
7. En la administración territorial, la participación se presenta con los artículos 311, que hace referencia a la vida municipal; el 318, sobre las Juntas Administrativas Locales; y el 323, sobre la conformación del Concejo del Distrito Capital.

8. Las entidades privadas sin ánimo de lucro pueden participar en la contratación administrativa, de conformidad con lo dispuesto por el artículo 355.

9. El artículo 210 permite la realización de funciones administrativas por parte de particulares.

10. Las acciones contra las autoridades públicas son permitidas por el artículo 92.

\section{CONCLUSIONES}

El propósito del presente ensayo era mostrar la relación entre la economía, la democracia y el Estado, para lo cual comenzamos con la caracterización de la economía colombiana como un sistema de mercado, y a partir de allí identificar las corrientes de pensamiento económico que se han presentado en la historia.

Con base en lo anterior iniciamos el proceso de la construcción del aparato estatal como resultado de la formación democrática, que se va a convertir en una característica del Estado representativo. Con estos elementos necesitábamos mostrar la relación que se presenta entre la economía, la democracia y el papel del Estado en materia económica en un Estado social de derecho, como es nuestro caso.

Después de este ensayo, espero que las preocupaciones sociales por las conductas estatales puedan encontrar un razonamiento teórico que permita comprender el funcionamiento del sistema democrático en el proceso de construcción del aparato estatal, y las funciones que debe cumplir el mismo para garantizar el desarrollo económico y el bienestar de la población. 


\section{BIBLIOGRAFÍA}

Ackley, G. (1968). Teoría Macroeconómica, (6ª Reimpresión). México: Biblioteca Uteha de Economía.

Arrellano, R. (1.993). Comportamiento del Consumidor y Marketing. Aplicaciones Prácticas para América Latina. México: Harla.

Centro Latinoamericano del Trabajo. (1969). La Economía del Trabajo. Bogotá: Editorial Tecniartes

Aristóteles. (1993). Política. Barcelona: Ediciones Altaya.

Branson, W. (1972). Teoría y Política Macroeconómica. México: Fondo de Cultura Económica.

Castaño, G. (1987). Teoría Económica General. Módulo Autoformativo. Bogotá: Escuela Superior de Administración Municipal.

Chesneis, F. (1997). Contribución al Debate sobre la Trayectoria del Capitalismo a finales del siglo XX. En

R. Vega, Una Defensa de la Historia y del Socialismo. Bogotá: Editor Marx y el siglo XXI.

Clavijo, S. (1998). Política Fiscal. En Estado en Colombia. Bogotá: Ediciones Uniandes.

Cuevas, H. (1977). Introducción a la Economía (5ª edición). Bogotá: Universidad Externado de Colombia.

Estrada, J. (1994). Planeación y Acumulación de Capital en Colombia, algunos Aspectos Jurídicos e Institucionales. Revista Hojas Económicas, 3.

Estrada, J. (1998). Reestructuración Económica y Coyuntura. Revista Su Versión, 7.

Esping, G. (1994). Los Tres Mundos del Estado del Bienestar. Valencia: Ediciones Alfons el Maggnámin,

Deane, P. (1993). El Estado y el Sistema Económico. Introducción a la Historia de la Economía Política.

Barcelona: Editorial Grijalba.

Ferguson, C.E. (1977). Teoría Microeconómica. México: Fondo de Cultura Económica.

Fischer, L. (1993). Mercadotecnia (2ª Edición). México: McGrawHill.

Friedman, M. (1996). Capitalismo y Libertad. Madrid: Rialp.

Gonnard, R. (1964). Historia de las Doctrinas Económicas. Madrid: Editorial Aguilar.

Hegel, G. W. (1994). Lecciones Sobre la Filosofía de la Historia Universal. Barcelona: Ediciones Altaya.

Lechner, N. (1992). El Debate Sobre Estado y Mercado. Revista Nueva Sociedad, 121.

Levi, B. (1997). ¿Qué puede hacer el Estado para impulsar los mercados? Finanzas y Desarrollo.

Lipietz, A. (1995). El Mundo del Posfordismo. Utopías, Revista de Debate Político, 166.

Malthus, R. (1993). Primer Ensayo Sobre la Población. Barcelona: Editorial Altaya.

Marx, C. (1979). El Capital. México: Fondo de Cultura Económica.

Montes, O. y Zuleta, G. (1994). Neoestructuralismo. Varios autores, Bogotá: Indepaz.

Moro, T. (1951). Utopía. México: Editorial Prorrua.

Platón. (1991). Las Leyes. México: Ediciones Porrua.

Platón. (1987). La República (2ª edición). Bogotá: Ediciones la montaña mágica.

Pradhan, S. (1997). Aumentar la Capacidad Institucional del Estado. Finanzas y Desarrollo, Washington, septiembre.

Ramírez, J. (2007). Las Finanzas Públicas en Colombia (5ª edición). Bogotá: Ediciones Librería del profesional.

Ramírez, J. (1999). Microeconomía para todos. Bogotá: Ediciones Jurídicas Gustavo lbáñez.

Ramírez, J. (2002). Macroeconomía para todos. Bogotá: Editorial Educativa-Fondo educativo Panamericano.

Ricardo, D. (1995). Principios de Economía Política. Madrid: Editorial Sarpe.

Rousseau, J. J. (1867). El Contrato Social. Bogotá: Editorial Versales, , 1867.

Salvatore, D. (1996). Microeconomía (3ª Edición). Bogotá: McGrawHill.

Smith, A. (1966). La Riqueza de las Naciones. Madrid: Editorial Alianza. 
Vargas, A. (1996). Planeación y Democracia en Colombia (6ª edición). Bogotá: Universidad Nacional de Colombia.

Toucard, J. (1990). Historia de las Ideas Políticas. México: Editorial Tecnos.

URSS. Academia de Ciencias de La URSS. (1969). Manual de Economía Política. México: Editorial Grijalbo. 